\title{
Characteristics of research in China assessed with Essential Science Indicators
}

\author{
Hui-Zhen Fu • Kun-Yang Chuang • Ming-Huang Wang • \\ Yuh-Shan Ho
}

Received: 24 January 2011 / Published online: 29 May 2011

(C) Akadémiai Kiadó, Budapest, Hungary 2011

\begin{abstract}
To provide an overview of the characteristics of research in China, a bibliometric evaluation of highly cited papers with high-level representation was conducted during the period from 1999 to 2009 based on the Essential Science Indicators (ESI) database. A comprehensive assessment covered overall performance, journals, subject categories, internationally collaborative countries, national inter-institutionally collaborative institutions, and most-cited papers in 22 scientific fields. China saw a strong growth in scientific publications in the last decade, to some extent due to increasing research and development expenditure. China has been more active in ESI fields of chemistry and physics, but more excellent in materials science, engineering and mathematics. Most publications were concerned with the common Science Citation Index subject categories of multidisciplinary chemistry, multidisciplinary materials and science, and physical chemistry. About one half China's ESC papers were internationally collaborative and the eight major industrialized countries (the USA, Germany, the UK, Japan, France, Canada, Russia, and Italy) played a prominent role in scientific collaboration with China, especially the USA. The Chinese Academy of Sciences took the leading position of institutions with many branches. The "985 Project" stimulated the most productive institutions for academic research with a huge funding injection and the universities in Hong Kong showed good scientific performance. The citation impact of internationally collaborative papers
\end{abstract}

\footnotetext{
H.-Z. Fu

Department of Environmental Engineering, Peking University, 100871 Beijing,

People's Republic of China
}

K.-Y. Chuang

Department of Public Health, Taipei Medical University, $250 \mathrm{Wu}-\mathrm{Hsing}$ Street, Taipei 11014, Taiwan

M.-H. Wang · Y.-S. Ho

Department of Environmental Sciences, The Key Laboratory of Water and Sediment Sciences, Ministry of Education, Peking University, 100871 Beijing, People's Republic of China

Y.-S. Ho $(\bowtie)$

Trend Research Centre, Asia University, No. 500, Lioufeng Road, Wufeng, Taichung County 41354, Taiwan

e-mail: ysho@asia.edu.tw 
differed among fields and international collaborations made positive contributions to academic research in China.

Keywords Bibliometric analysis - China - Essential science indicator · Highly cited papers

\section{Introduction}

China is one of the most attractive countries in terms of scientific performance today (Huang 2010; Mervis 2010). It has experienced a sustained and remarkable increase in scientific production (Jin and Rousseau 2005; Zhou and Leydesdorff 2006) and became the global second largest producer of scientific publications since 2006 (Zhou and Leydesdorff 2008), particularly taking a world-leading position in special fields now (Zhou and Leydesdorff 2009; Malarvizhi et al. 2010). However, many prior studies restricted to the China's scientific performance of global research position (Jin and Rousseau 2005; Zhou and Leydesdorff 2006, 2008, 2009), performance of specific fields (Guan and Ma 2007a, b; Chen et al. 2007; Zhou and Leydesdorff 2009), international collaboration of China (Zhou and Glanzel 2010) or between China and particular countries (He 2009), and investment in science and technology (Mervis 2010) by China's Science Citations Index (SCI) papers. The characteristics of fields, journals, subject categories, international collaboration partners, national inter-institutional collaboration players and most-cited papers of China's highly cited papers, more specifically and typically, remain systematically underinvestigated. To understand these elements, this study used bibiliometric methods based on China's highly cited papers, provided by Essential Science Indicators (ESI) of the Institute for Scientific Information (ISI), which has been recently attempted to identify the scientific disciplines in the research of countries (Soteriades and Falagas 2005; Jeenah and Pouris 2008; Almeida et al. 2009).

Bibliometric methods as a common research tool has been widely used to measure the scientific performance of countries (Schubert et al. 1989; Pouris 1989; Yamazaki 1994; Moed et al. 1995; Glänzel, 1996; de Haan 1997; Glänzel 2000; Guan and Gao 2008). Measuring aspects usually covered research specialities with journals (Pouris 1989; Schubert et al. 1989; Moed et al. 1995; Yamazaki 1994; Guan and Gao 2008), subject categories (Pouris 1989; Schubert et al. 1989; Yamazaki 1994; Moed et al. 1995), collaborative countries and institutions (Schubert et al. 1989; Yamazaki 1994; Moed et al. 1995; Glänzel 1996, 2000; de Haan 1997; Guan and Gao 2008). Furthermore, most-cited papers with a significant influence in related fields have been investigated in recent bibliometric literatures (Paladugu et al. 2002; Baltussen and Kindler 2004; Hannerz 2010; Ponce and Lozano 2010; Shadgan et al. 2010).

Bibliometric indicators provide a reliable evidence and panorama of scientific activity. Number of publications is considered to be indications of scientific production (Vinkler 1988; Rinia et al. 1998). Citations-based indicators, as valuable and revealing measures of the impact and internationalization of the scientific work (Martin and Irvine 1983; Moed et al. 1985; Moed 2005; Vinkler 1988; Garfield and Welljams-Dorof 1992), have been used in various research topics such as sociology (Cronin et al. 1997), materials science (Garfield and Pudovkina 2003), and hydrogeology (Schwartz and Fang 2007). Citation analysis is more formal, open, scholarly founded, supplemented in the evaluation of groups (Moed 2005). The citation based indicators including number of citations (Moed 2005; Rehn et al. 2007), citations per publication (Moed et al. 1985; Seng and Willett 1995; Katz 
and Hicks 1997) and peak year citations per publication (Hsieh et al. 2004; Chiu and Ho 2005; Li and Ho 2008) have been applied in various studies. The indicator, average citations per publication is more useful than the total citations for uncovering peak citation trends (Zhou et al. 2007). Impact factor has the advantage of already being in existence and is a good indicator for scientific evaluation (Hoeffel 1998). Moreover, five indicators, total number, independent, collaborative, first author, and corresponding author articles by countries and institutions were innovatively used to explore the performance of scientific research in recent research, providing diversified information for evaluation (Ho et al. 2010; Hu et al. 2010; Mao et al. 2010; Zhang et al. 2010).

Accordingly, a bibiliometric analysis of highly cited papers originating from China was conducted based on the ESI database. The main body of this study is divided into five parts, aiming at identify the characteristics of China ESI papers covering fields performance, disciplinary strength, international collaboration and national inter-institutional collaboration, and most cited papers. First, the overall scientific performance of China in terms of ESI papers distributed in 22 fields was conducted. The second section dealt with publication activity, with major focus on favored journals and subject categories, while China's major international collaboration partners and national inter-institutional collaboration players were identified in the third and fourth sections, respectively. Finally, the most cited papers in each field are examined as a statement of discipline emphases and impact.

\section{Method}

The data of Chinese highly cited papers analyzed in this paper are all obtained from ESI. The ESI includes the papers with a number of citations in the top $1 \%$ in specific fields for each year in the 10-period surveyed, providing access to a unique and comprehensive compilation of essential science performance statistics and science trends. Highly cited papers are selected based on percentile rankings specific to their fields of study. Data of ESI database are updated bimonthly (six times a year). The analyzed time span in this study was updated in November 2, 2009, covering the 10-year plus 8-month period from January 1, 1999 to August 31, 2009. "Peoples R China" was employed as the keyword to search countries/territories, and therefore a total of 4,269 ESI papers where at least one of the authors has a Chinese address (including Hong Kong) were extracted from the ESI database.

For each paper, downloaded information included all contributing authors, all their addresses, source data (journal title, subject category, fields, publication year and document type), and title of the publication. The records were downloaded into spreadsheet software (Microsoft Excel 2007), and additional coding was manually performed for institutions and countries of origin of the coauthored articles. Coauthored articles, as indicators of collaboration across institutions in the country and internationally (NSF report 2010; www.nsf.gov), including "internationally collaborative publication" and "interinstitutionally collaborative publication". As for following analysis, collaboration type was determined by the addresses of the authors, where the term "China independent publication" was assigned if the researchers' addresses were all from China. The term "internationally collaborative publication" was designated to those articles that were coauthored by researchers from China and other countries. The term "institute independent publication" was assigned if the researchers' addresses were from the same institute in China. The term "inter-institutionally collaborative publication" was assigned if authors were from different institutes which included at least one institute in China. In addition, papers 
originating from England, Scotland, Northern Ireland, and Wales were reclassified as being from the United Kingdom (UK).

The bibliometric indicators calculated in the study on China's academic papers are given in Table 1 together with their denotation, definition and calculation. Publication outputs indicators (including number of publication and publication share) and citation indicators (including number of citation, citations per publication, highest number of citations) were mainly used, and some other indicators (including impact factor of journal and ranking) were also employed. Indicators related to "China independent publications" or "institute independent publications" of China's ESI papers $\left(P_{S C P}\right.$, $\left.C C P_{S C P}, R_{P_{S C P}}, \%_{P_{S C P}}\right)$, and "internationally collaborative publications" or "inter-institutionally collaborative publications" of China's ESI papers $\left(P_{C C P}, C C P_{C C P}, R_{P_{C C P}}\right.$, $\left.\%_{P_{C C P}}\right)$, first author of the publication by country or institution $\left(R_{P_{F A}}\right)$ corresponding author of the publication by country or institution $\left(R_{P_{R P}}\right)$ were innovatively to describe the visibility and strength of highly cited papers of one country. $C_{2009}$, as an evaluation indicator used, has an advantage that it with a fixed value can be checked at any time. All these indicators were processed by Microsoft Excel 2007 with functions including PivotTable, text to columns, sort, filter, concatenate, sum, rank, vlookup, proper, and match. To be more specific, the analytic structure of characteristics of China's ESI papers is presented in Fig. 1.

\section{Results and discussion}

\section{Overall scientific performance}

The overall scientific performance of highly cited papers from the ESI including document types, first author and corresponding author of papers having a China's address and fields was identified. Figure 2 illustrates the percentage of different document types (proceedings papers, reviews, and articles). The distribution of document types was 3,738 (88\% of 4,269 ESI papers from China) articles, $416(10 \%)$ reviews, and $115(2.7 \%)$ proceedings papers. The percentage of ESI articles to the total ESI papers from China fluctuated around $87 \%$ and saw an upward trend from 2006 to 2009. Clearly, scientific research in China has developed steadily in recent years, similar to the results of another related study (Zhou and Leydesdorff 2006). The percentage of first author and corresponding author papers originating from China also showed an overall increasing trend (Fig. 3), which enforces the view that China's innovative activities have been strengthened. Over the last two decades, China has experienced strong and sustained economic growth with Gross Domestic Product (GDP) growth around 9\% (http://www.stats.gov.cn/). It is no coincidence that economic growth and research performance are highly correlated in China (Zhou and Leydesdorff 2008). The percentage of GDP spent on research may influence publication outputs (Halpenny et al. 2010). The Chinese government focused on science and technology to substantially increasing the expenditure on research and development as a percentage of GDP, from $0.6 \%$ in 1996 to $1.5 \%$ by 2007, just behind the USA and Japan, according to the 2010 edition of Science and Engineering Indicators (www.nsf.gov/nsb/sei). It was also reported that the size of China's scientific workforce now equals that of the USA and the European Union, and it is argued that China ranks first on key global scientific indicators because science and technology spending has risen by $20 \%$ annually for more than a decade (Mervis 2010). 
Table 1 Introduction of the bibliometric indicators used in subsequent analysis

\begin{tabular}{|c|c|c|c|}
\hline Indicators & Denotation & Definition & Calculation \\
\hline \multirow[t]{5}{*}{$\begin{array}{l}\text { Number of } \\
\text { publication }\end{array}$} & $P_{S C I-C}$ & $\begin{array}{l}\text { Number of scientific publications of China produced } \\
\text { by the analyzed unit during the analyzed time span } \\
\text { in the Thomson SCI indices (China's SCI papers) } \\
\text { (Rehn et al. 2007) }\end{array}$ & $\begin{array}{l}\text { Counting the } \\
\text { number of } \\
\text { publications }\end{array}$ \\
\hline & $P_{E S I-C}$ & $\begin{array}{l}\text { Number of scientific publications of China produced } \\
\text { by the analyzed unit during the analyzed time span } \\
\text { in the Thomson ESI indices (China's ESI papers) } \\
\text { (Rehn et al. 2007) }\end{array}$ & $\begin{array}{l}\text { Counting the } \\
\text { number of } \\
\text { publications }\end{array}$ \\
\hline & $P_{E S I-W}$ & $\begin{array}{l}\text { Number of scientific publications in the world } \\
\text { produced by the analyzed unit during the analyzed } \\
\text { time span in the Thomson ESI indices (World's } \\
\text { ESI papers) (Rehn et al. 2007) }\end{array}$ & $\begin{array}{l}\text { Counting the } \\
\text { number of } \\
\text { publications }\end{array}$ \\
\hline & $P_{S C P}$ & $\begin{array}{l}\text { Number of "China independent publications" or } \\
\text { "institute independent publications" of China's } \\
\text { ESI papers }\end{array}$ & $\begin{array}{l}\text { Counting the } \\
\text { number of } \\
\text { publications }\end{array}$ \\
\hline & $P_{C C P}$ & $\begin{array}{l}\text { Number of "internationally collaborative } \\
\text { publications" or "inter-institutionally } \\
\text { collaborative publications" of China's ESI papers }\end{array}$ & $\begin{array}{l}\text { Count the number } \\
\text { of publications }\end{array}$ \\
\hline \multirow[t]{4}{*}{$\begin{array}{l}\text { Publication } \\
\text { share }\end{array}$} & $\%$ & $\begin{array}{l}\text { Number of China's ESI papers of an actor (journal, } \\
\text { country/territory, institution) as a share of the total } \\
\text { number of China's ESI papers (Rehn et al. 2007) }\end{array}$ & $\begin{array}{l}\left(P_{E S I-C} \text { of one }\right. \\
\text { actor }) / P_{E S I-C}\end{array}$ \\
\hline & $\% P_{S C P}$ & $\begin{array}{l}\text { The given field's number of China independent } \\
\text { papers as a share of given field's the total China's } \\
\text { ESI papers }\end{array}$ & $\begin{array}{l}P_{S C P} / P_{E S I-C} \\
\quad \text { (Given field) }\end{array}$ \\
\hline & $\%_{P_{C C P}}$ & $\begin{array}{l}\text { The given field's number of China's internationally } \\
\text { collaborative papers as a share of given field's } \\
\text { number of the China's ESI papers }\end{array}$ & $\begin{array}{l}P_{C C P} / P_{E S I-C} \\
\quad \text { (Given field) }\end{array}$ \\
\hline & $\% P_{E S I-C}-P_{E S I-W}$ & $\begin{array}{l}\text { The given journal's number of China's ESI papers } \\
\text { as a share of the given journal's number of World } \\
\text { ESI papers }\end{array}$ & $\begin{array}{l}P_{E S I-C} / P_{E S I-W} \\
\quad \text { (Given journal) }\end{array}$ \\
\hline \multirow[t]{2}{*}{ Activity index } & $A I_{P_{E S I-C}-P_{S C I-C}}$ & $\begin{array}{l}\text { The given field's share in China's ESI papers } \\
\text { proportional to the given field's share in China's } \\
\text { SCI papers (Glänzel 2000) }\end{array}$ & $\begin{array}{l}P_{E S I-C} / P_{S C I-C} \\
\quad(\text { Given field) }\end{array}$ \\
\hline & $A I_{P_{E S I-C}-P_{E S I-W}}$ & $\begin{array}{l}\text { The given field's share in China's ESI papers } \\
\text { proportional to its share of publications of World's } \\
\text { ESI papers (Glänzel 2000) }\end{array}$ & $\begin{array}{l}\text { Ratio: } P_{E S I-C} \\
P_{E S I-W}(\text { Given } \\
\text { field }) .\end{array}$ \\
\hline \multirow[t]{2}{*}{$\begin{array}{l}\text { Number of } \\
\text { citations }\end{array}$} & $C$ & $\begin{array}{l}\text { The total number of citations to China's SCI papers } \\
\text { during the analyzed time span (Rehn et al. 2007) }\end{array}$ & Web of Science \\
\hline & $C_{2009}$ & $\begin{array}{l}\text { The total number of citations to China's ESI papers } \\
\text { from its publication year to } 2009\end{array}$ & Web of Science \\
\hline \multirow{3}{*}{$\begin{array}{l}\text { Citations per } \\
\text { publication } \\
\text { (CPP) }\end{array}$} & $C P P_{S C I}$ & $\begin{array}{l}\text { Average number of citations per China's SCI paper } \\
\text { (Moed et al. 1985) }\end{array}$ & $C / P_{S C I-C}$ \\
\hline & $C C P_{S C P}$ & $\begin{array}{l}\text { Average number of citations per "China } \\
\text { independent publication" or "institute } \\
\text { independent publication" }\end{array}$ & $C_{S C P} / P_{E S I-C}$ \\
\hline & $C C P_{C C P}$ & $\begin{array}{l}\text { Average number of citations to per "internationally } \\
\text { collaborative publication" or "inter-institutionally } \\
\text { collaborative publication" }\end{array}$ & $P_{C C P} / P_{E S I-C}$ \\
\hline
\end{tabular}


Table 1 continued

\begin{tabular}{|c|c|c|c|}
\hline Indicators & Denotation & Definition & Calculation \\
\hline \multirow[t]{3}{*}{$\begin{array}{l}\text { Highest } \\
\text { number of } \\
\text { citations }\end{array}$} & $H C_{C}$ & $\begin{array}{l}\text { The highest number of citations of China's ESI } \\
\text { paper }\end{array}$ & $\begin{array}{l}\text { Sequencing by } \\
\text { number of } \\
\text { citations }\end{array}$ \\
\hline & $H C_{W}$ & $\begin{array}{l}\text { The highest number of citations of World's ESI } \\
\text { papers }\end{array}$ & $\begin{array}{l}\text { Sequencing by } \\
\text { number of } \\
\text { citations }\end{array}$ \\
\hline & $\% H C_{C}-H C_{W}$ & $\begin{array}{l}\text { Highest number of citations China's ESI papers as a } \\
\text { share of the highest of World's ESI papers }\end{array}$ & $H C_{C} / H C_{W}$ \\
\hline Impact factor & IF & $\begin{array}{l}\text { Average number of times articles from the journal } \\
\text { published in the past two years has been cited in } \\
\text { the Journal Citation Reports (JCR) year }\end{array}$ & Web of Science \\
\hline \multirow[t]{6}{*}{ Ranking } & $R_{C P P}$ & Ranking of citations per publication by fields & $\begin{array}{l}\text { Sequencing by } \\
\text { CPP }\end{array}$ \\
\hline & $R_{P_{E S I-C}}$ & $\begin{array}{l}\text { Ranking of number of China's ESI papers by } \\
\text { countries or institutions }\end{array}$ & $\begin{array}{l}\text { Sequencing by } \\
\text { CPP }\end{array}$ \\
\hline & $R_{P_{S C P}}$ & $\begin{array}{l}\text { Ranking of number of "China independent } \\
\text { publications" by countries or "institute } \\
\text { independent publications" by institutions }\end{array}$ & $\begin{array}{l}\text { Sequencing by } \\
\text { CPP }\end{array}$ \\
\hline & $R_{P_{C C P}}$ & $\begin{array}{l}\text { Ranking of number of "internationally collaborative } \\
\text { publication" by countries or "inter-institutionally } \\
\text { collaborative publication" by institutions }\end{array}$ & $\begin{array}{l}\text { Sequencing by } \\
\text { CPP }\end{array}$ \\
\hline & $R_{P_{F A}}$ & $\begin{array}{l}\text { Ranking of number of publications by countries or } \\
\text { institutions originated first author of one } \\
\text { publication }\end{array}$ & $\begin{array}{l}\text { Sequencing by } \\
\text { CPP }\end{array}$ \\
\hline & $R_{P_{R P}}$ & $\begin{array}{l}\text { Rank of number of publications by countries or } \\
\text { institutions originated corresponding author of one } \\
\text { publication }\end{array}$ & $\begin{array}{l}\text { Sequencing by } \\
\text { CPP }\end{array}$ \\
\hline
\end{tabular}

Research outputs obtained from the SCI of the ISI in the 22 fields over the last 10 years (January 1, 1999 to August 31, 2009) are shown in Table 2. In terms of quantity, the field of chemistry ranked 1st with 158,668 papers, followed by physics $(102,515)$, material science $(75,699)$, engineering $(69,896)$, and clinical medicine $(48,915)$. This meant a large amount of research on chemistry, physics, material science, engineering, and clinical medicine was conducted in China in recent years. Besides, a comparison covering the quantity, the highest citations in 22 fields of ESI papers from China and the world are displayed (Table 2). Engineering and mathematics were the top two fields with the highest value of share of publications of China's ESI papers proportional to its share of publications the field of China's SCI papers $\left(A I_{P_{E S I-C}-P_{S C I-C}}\right)$ and having values of 1.8 and 1.6. Materials science have the highest value of share of publications of China's ESI papers proportional to its share of publications of World's ESI papers $\left(\% P_{E S I-C}-P_{E S I-W}\right) 2.8$, followed closely by mathematics 2.6 and engineering 2.5. In terms of $\%_{H C_{C}-H C_{W}}$, percentage of the highest number of citations of ESI papers from China and the world, Computer science ranked 1st with $98 \%$ and molecular biology \& genetics ranked 2nd with 96\%. Moreover, the papers with the highest numbers of citations in engineering, immunology, and materials science were independent without international collaboration. The collaborative countries with the highest number of citations of ESI papers from China $\left(\right.$ Country $_{H C_{c}}$ ) and the world $\left(\right.$ Country $_{H C_{W}}$ ) shows that the USA was quite active in most fields. 


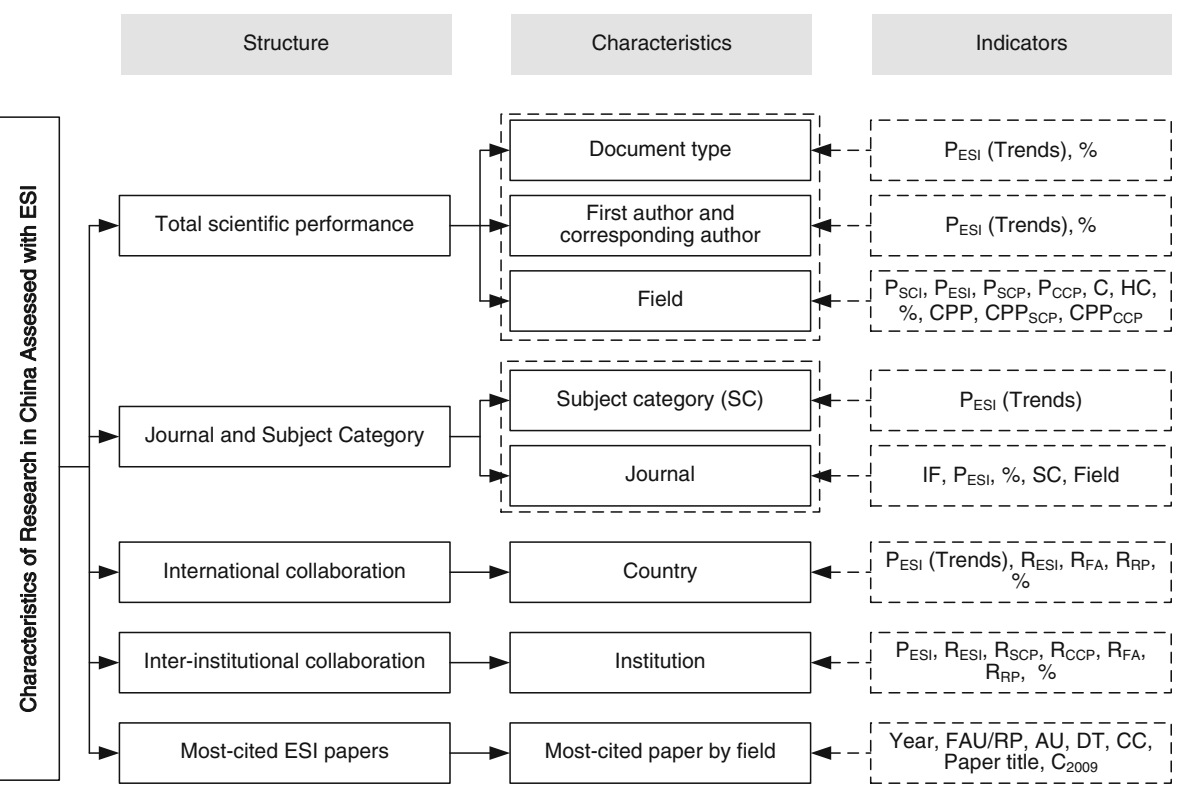

Fig. 1 Analytic structure of characteristics of research in China assessed with ESI

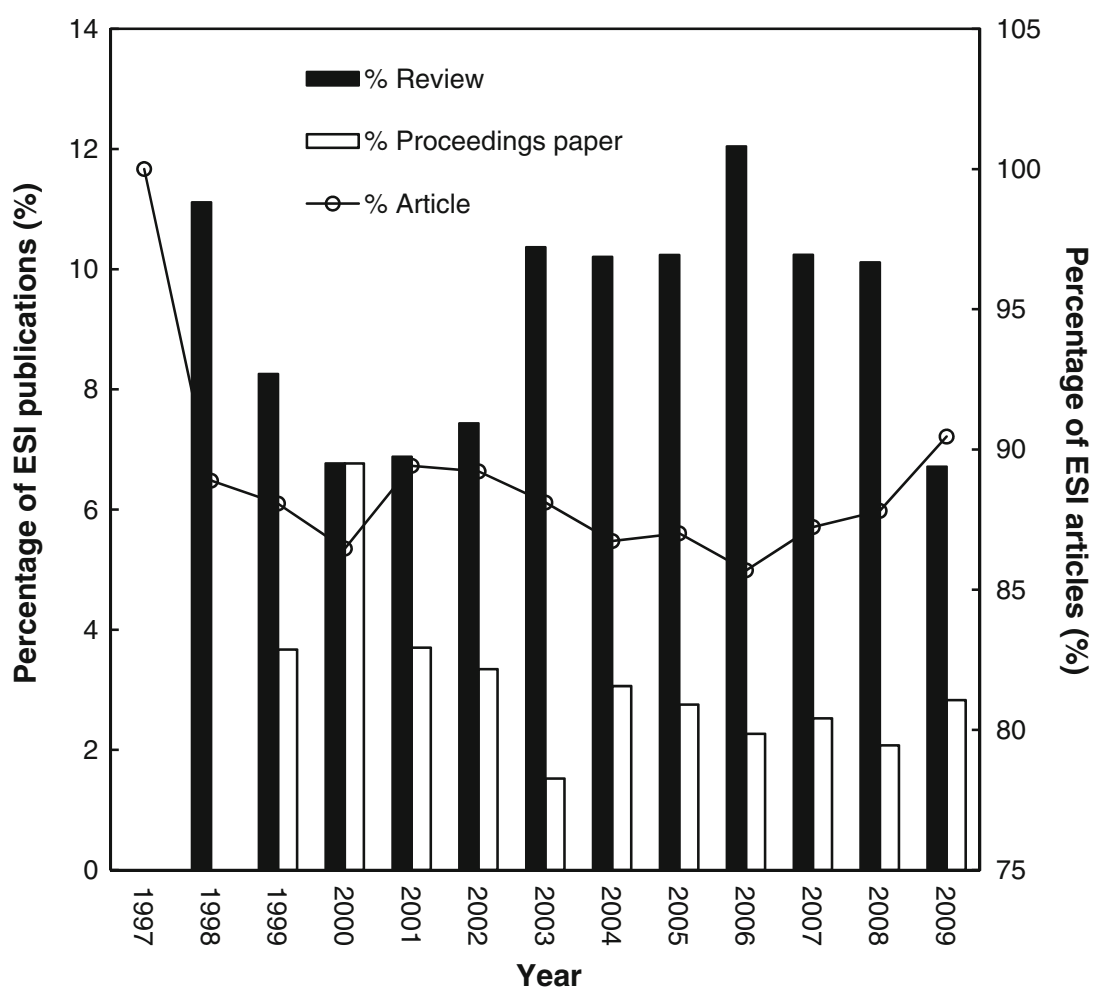

Fig. 2 Pattern of the distribution of document types in the ESI 


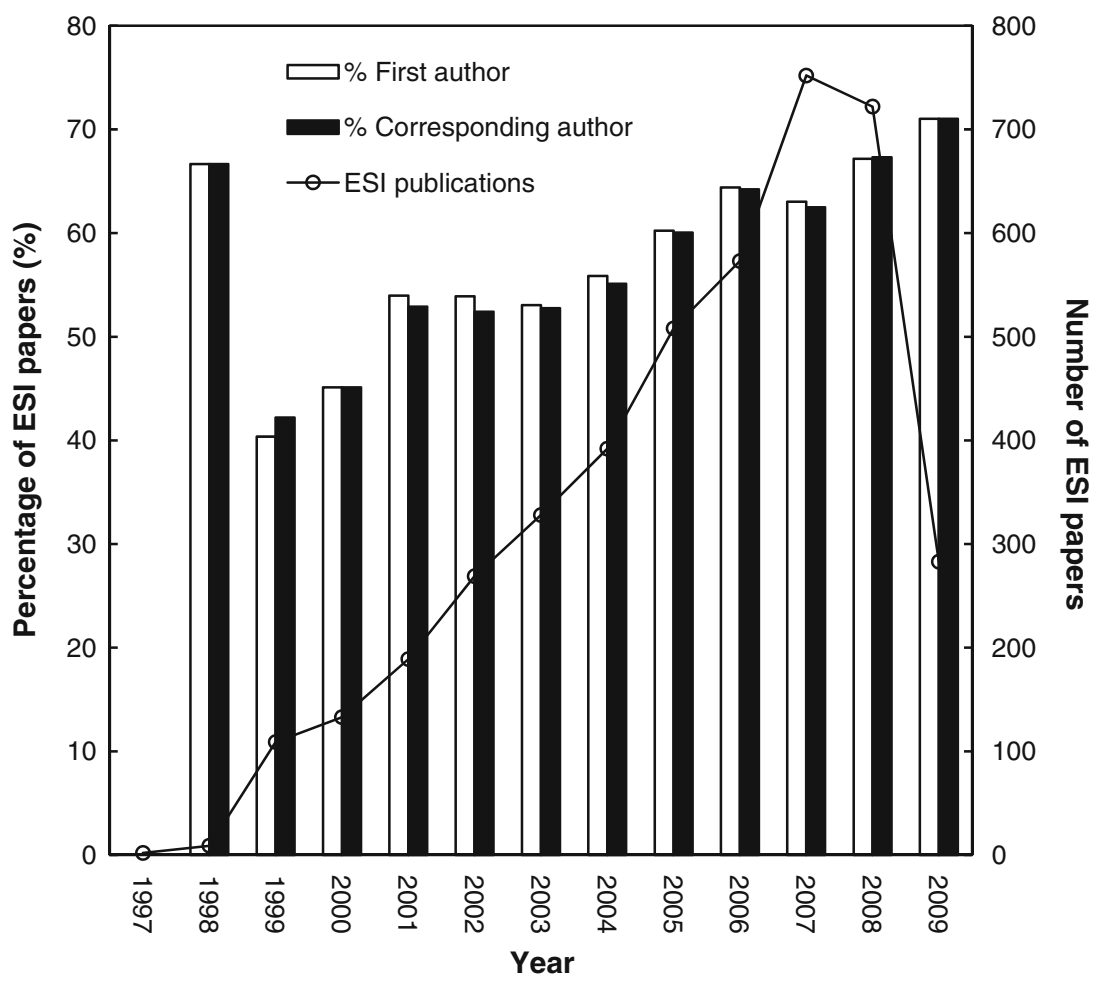

Fig. 3 The distribution of first author and corresponding author papers in the ESI

Citations of papers of China's SCI papers (January 1, 1999 to August 31, 2009), publication outputs and citations of independent and internationally collaborative papers in 22 fields of China's ESI papers are described in Table 3. The order of citations per paper by 22 fields differed by disciplines, with molecular biology \& genetics ranking 1st with 9.83 citations per paper, followed by neuroscience \& behavior (8.19), clinical medicine (7.77), microbiology (7.57), immunology (7.14), and psychiatry/psychology (7.08). Generally, China published 649,689 papers with an average of 5.24 citations per paper. Scientists in China in most fields publish in scientific journals with a lower citation impact than the world average and have a lower citation rate than expected (Glänzel et al. 2002). China's science needs to move from the 'quantitative expansion' phase in which it is nowadays to a 'rising quality' phase (Jin and Rousseau 2005). As for China's ESI papers, chemistry had the highest percentage of independent papers among total papers with $72 \%$, followed by materials science with $69 \%$ and engineering with $62 \%$. China has developed rapidly in chemical research and has taken a leading position in publishing journal papers (Zhou and Leydesdorff 2009). Due to the national policy in the past, the fields of chemistry, physics, and engineering and mathematics had developed better (Glänzel et al. 2002). Especially, there were no independent ESI papers in immunology and neuroscience \& behavior. Simultaneously, there are high percentages of 95 and $96 \%$ of collaborative ESI papers in molecular biology \& genetics and general social sciences.

The average citation of one collaborative paper appeared higher than an independent paper in most of the 18 fields but not four fields including agricultural sciences, 


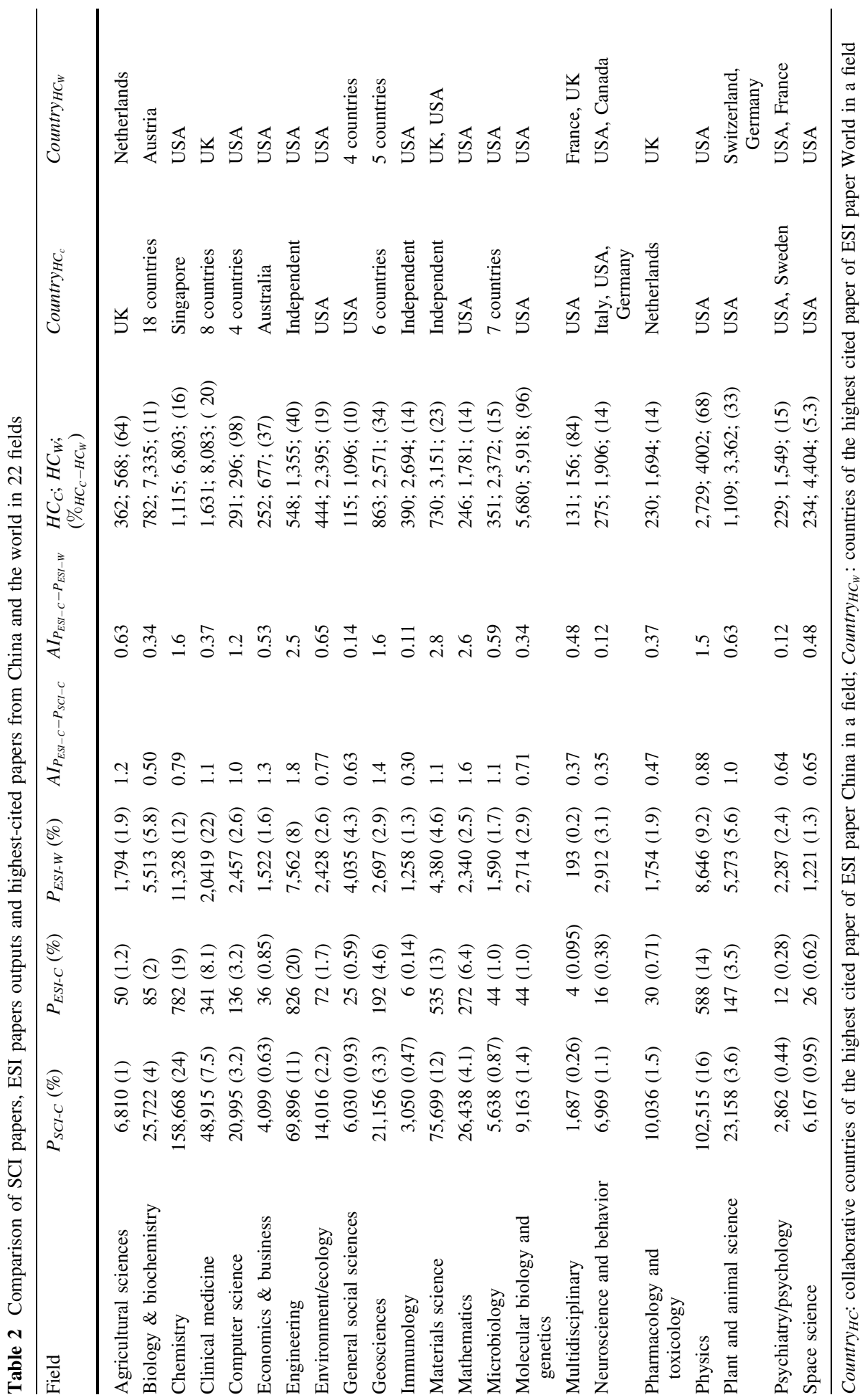


Table 3 Independent and collaborative country papers of China ESI papers in 22 fields

\begin{tabular}{|c|c|c|c|c|c|}
\hline Field & $\begin{array}{l}C P P_{S C I} \\
\left(R_{C P P}\right)\end{array}$ & $\begin{array}{l}P_{S C P} \\
\left(\% P_{S C P}\right)\end{array}$ & $\begin{array}{l}C C P_{S C P} \\
\left(R_{C P P}\right)\end{array}$ & $\begin{array}{l}P_{C C P} \\
\left(\% P_{C C P}\right)\end{array}$ & $\begin{array}{l}C C P_{C C P} \\
\left(R_{C P P}\right)\end{array}$ \\
\hline Agricultural sciences & $4.47(16)$ & $25(50)$ & $49(15)$ & $25(50)$ & $49(20)$ \\
\hline Biology and biochemistry & $6.6(7)$ & $30(35)$ & $106(3)$ & $55(65)$ & $134(4)$ \\
\hline Chemistry & $5.87(10)$ & $566(72)$ & $103(4)$ & $216(28)$ & $115(9)$ \\
\hline Clinical medicine & $7.77(3)$ & $95(28)$ & $152(2)$ & $246(72)$ & $168(2)$ \\
\hline Computer science & $1.91(22)$ & $64(47)$ & $76(11)$ & $72(53)$ & $104(11)$ \\
\hline Economics and business & $5.02(14)$ & $6(17)$ & $25(18)$ & $30(83)$ & $73(17)$ \\
\hline Engineering & 3.49 (18) & $515(62)$ & $51(14)$ & $311(38)$ & $66(19)$ \\
\hline Environment/ecology & $5.81(11)$ & $32(44)$ & $80(9)$ & $40(56)$ & $79(16)$ \\
\hline General social sciences & $3.42(19)$ & $1(4.0)$ & 39 (16) & $24(96)$ & $37(22)$ \\
\hline Geosciences & $6.11(9)$ & $45(23)$ & $82(8)$ & $147(77)$ & $121(7)$ \\
\hline Immunology & $7.14(5)$ & $0(0)$ & N/A & $6(100)$ & $130(5)$ \\
\hline Materials science & $4.11(17)$ & $368(69)$ & $77(10)$ & $167(31)$ & $84(14)$ \\
\hline Mathematics & $2.66(20)$ & $144(53)$ & $30(17)$ & $128(47)$ & $40(21)$ \\
\hline Microbiology & $7.57(4.0)$ & $10(23)$ & $91(7)$ & $34(77)$ & $123(6)$ \\
\hline $\begin{array}{l}\text { Molecular biology and } \\
\text { genetics }\end{array}$ & $9.83(1)$ & $2(4.5)$ & $308(1)$ & $42(95)$ & $349(1)$ \\
\hline Multidisciplinary & $2.37(21)$ & $1(25)$ & $103(4)$ & $3(75)$ & $94(12)$ \\
\hline Neuroscience and behavior & $8.19(2)$ & $0(0)$ & N/A & $16(100)$ & $118(8)$ \\
\hline Pharmacology and toxicology & $5.78(12)$ & $16(53)$ & $69(12)$ & $14(47)$ & $82(15)$ \\
\hline Physics & $5.22(13)$ & $291(49)$ & $102(6)$ & $297(51)$ & $138(3)$ \\
\hline Plant and animal science & $4.68(15)$ & $47(32)$ & $59(13)$ & $100(68)$ & $90(13)$ \\
\hline Psychiatry/psychology & $7.08(6)$ & $4(33)$ & $15(20)$ & $8(67)$ & $73(17)$ \\
\hline Space science & $6.22(8)$ & $5(19)$ & $21(19)$ & $21(81)$ & $109(10)$ \\
\hline
\end{tabular}

N/A not available

environment/ecology, multidisciplinary, and general social sciences. This phenomenon that collaborative papers get more citations than independent papers was also noted in other studies (Katz and Hicks 1997; Zhou and Leydesdorff 2009). Collaboration is a less important factor contributing to high impact in research specialties, and makes a stronger contribution to high impact in papers from small countries within them (Persson 2010). The feature that collaboration seems more promising in producing highly cited papers in major fields of China support the recommendation to stimulate international collaborations. On the other hand, the independent research level in China increased the independent paper citations. Synthetically considering the indicators of outputs and citations of China's ESI papers, research in China played well in the fields of chemistry, materials science, mathematics, and engineering.

Characteristics of research journal and subject category

Journal Citation Reports (JCR) indexed 6,620 major journals with citation references across 173 scientific disciplines in 2008. Based on the classification of subject categories in JCR, the ESI papers from China were distributed in 137 subject categories.

A continuous increase was shown in each subject category except for 1997 and 2009 (Fig. 4). The two most common categories were multidisciplinary with 1,106 papers 


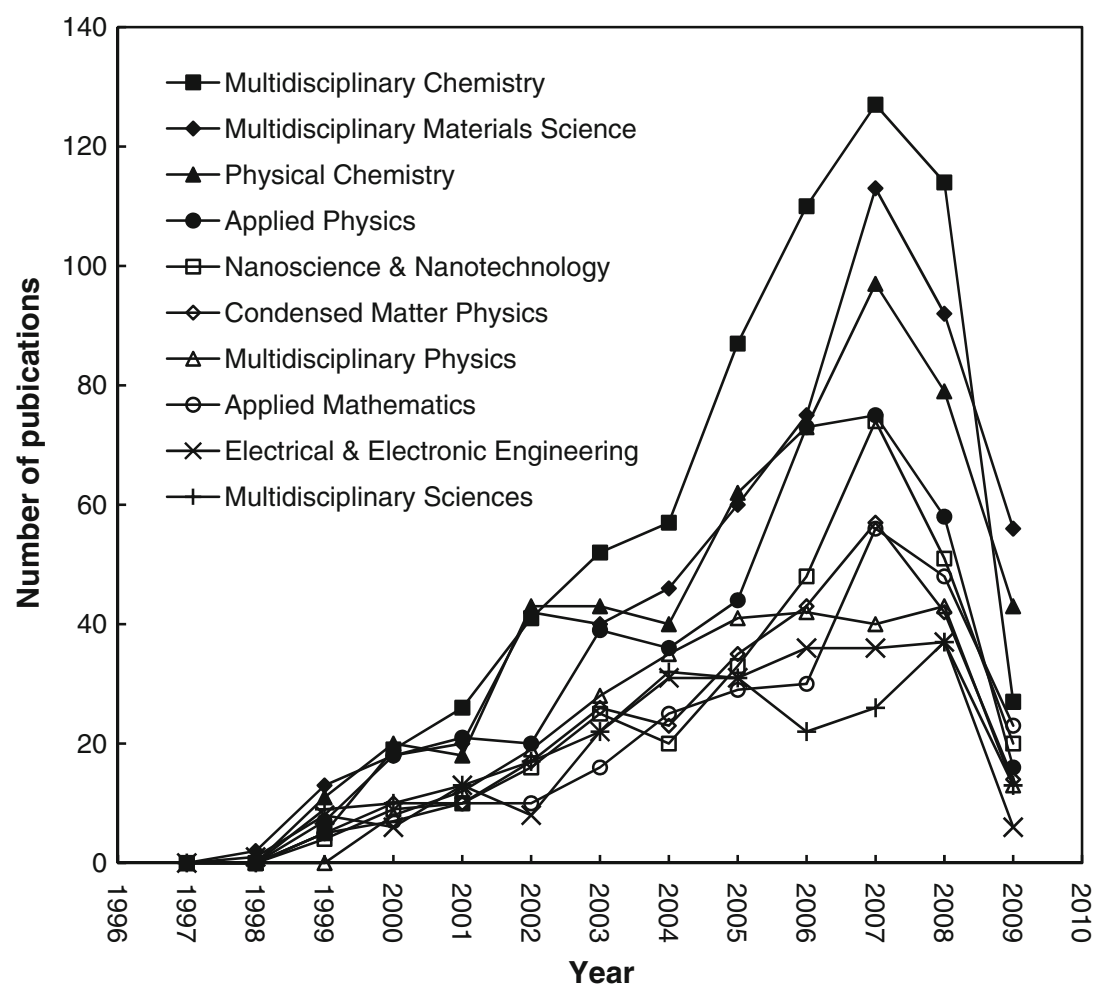

Fig. 4 Comparison of the growth trends of the top ten productive subject categories

(26\% of all ESI papers from China), namely multidisciplinary chemistry and multidisciplinary materials and science, followed closely by physical chemistry with 407 (10\%). Multidisciplinary chemistry ranked 1st from 2003 to 2008 but declined slightly to 3rd in 2009.

The journal literature can be used for quantitative comparison of publication activity in any scientific field and sub-field if the sources and methods used are characteristic of all the countries investigated and the number of processed items (journal articles, citations) is statistically significant (Glänzel et al. 2002). Top 20 highly cited papers from China in productive journals are listed in Table 4 showing the impact factor, number of publications, publication share, subject categories and fields. The top three journals based on the number ranking of highly cited papers was Advanced Materials (140) in six subject categories, the Journal of the American Chemical Society (131) in multidisciplinary chemistry and Physical Review Letters (127) in multidisciplinary physics, while the top three journals for the percentage ranking of ESI papers from China to the total number of world ESI was the Journal of Mathematical Analysis and Applications (40\%) with an impact factor of 8.191 in the applied mathematics and mathematics category, Inorganic Chemistry (36\%) in inorganic \& nuclear chemistry, and Advanced Functional Materials (27\%) in six subject categories. Most journals appeared in the multidisciplinary subject category. Excluding three journals (Nature, Science, and Proceedings of the National Academy of Sciences of the United States of America) covering more than one field, each of the other 17 journals focused on only one field. The fields listed included materials science, chemistry, physics, 


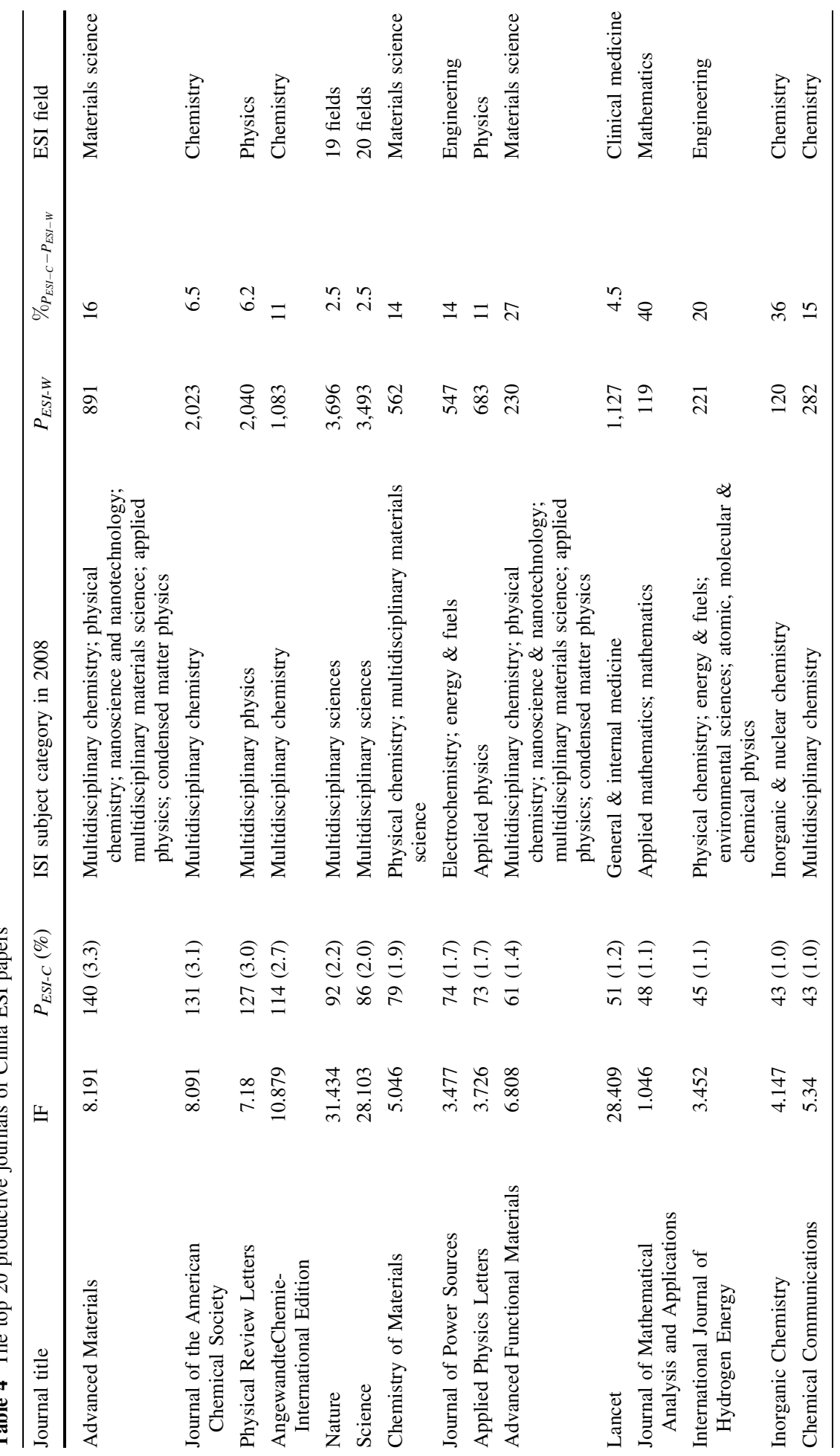




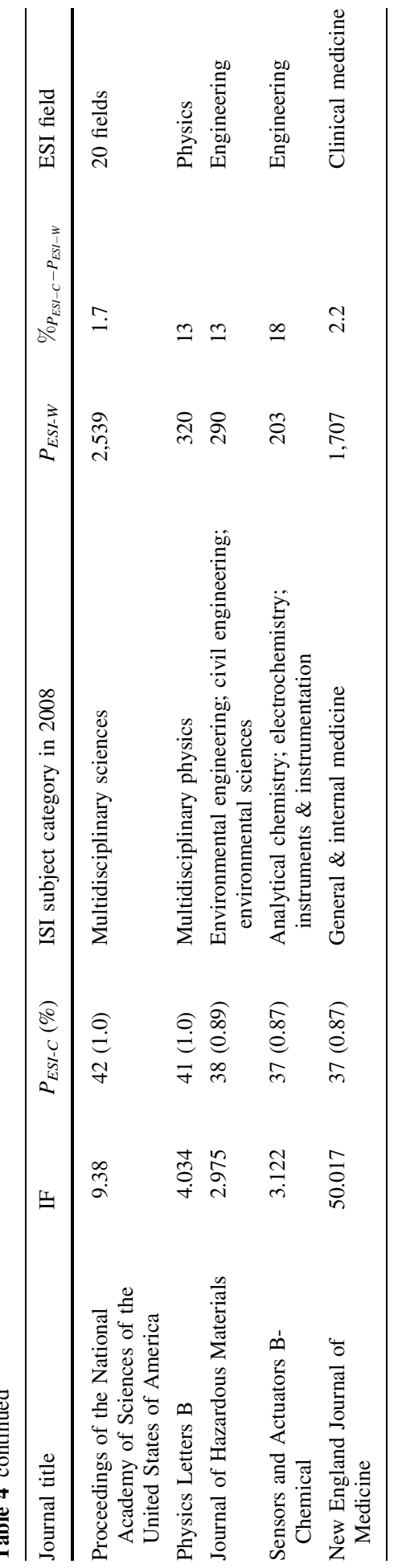


engineering, clinical medicine and mathematics. This finding is consistent with the above results for overall scientific performance.

\section{International collaboration}

After reviewing the overall performance on total publications, characteristics of journals and subject categories, collaborative countries and national institutions were analyzed in order to investigate the situation of Chinese international collaboration and domestic activity. Collaboration plays a growing role in scientific research and usually manifests itself in internationally co-authored publications revealed by bibliometric tools (Schubert and Braun 1990). A total of 2,267 (53\% of all ESI papers from China) ESI papers were China independent publications and 2,002 (47\%) were internationally collaborative. National share of internationally co-authored publications of China SCI papers is $23.7 \%$ in 2002 and 21.9\% in 2007 (Zhou and Glanzel 2010), just about one half of that of China ESI papers, which implied that international collaboration benefits scientific papers. It is also reported that highly cited papers typically involve more collaborative research than what is the normal or average at an aggregated, general level (Aksnes 2003). A total of 3,013 (71\%) ESI papers had Chinese first authors and 3,006 (71\%) had Chinese corresponding authors. The 20 countries most frequently collaborating with China are listed in Table 5. The eight major industrialized countries (G8), the USA, Germany, the UK, Japan, France, Canada, Russia, and Italy ranked in the top 9 internationally collaborative countries, accounting for around $84 \%$ of China internationally collaborative ESI papers. Similarly, the phenomenon of the seven major industrialized countries (G7) the USA, Germany, the UK, Japan, France, Canada, and Italy accounted for a significant proportion is common (Li et al. 2009b; Fu et al. 2010; Wang et al. 2010; He 2009). The important international collaboration pattern of China and G7 which is also existed for SCI papers in the web of science and the descending orders of outputs for China SCI papers with the G7 countries on international collaboration are USA, Japan, Germany, England, Canada, France and Italy (He 2009). The concretely increasing trends of G8 indicated that China intensified academic exchanges with these countries in recent decade (Fig. 5). The USA dominated with 1,215 papers, ranking 1st in both first author and responding author in China ESI papers, followed distantly by other countries. The USA has many highly cited papers and appears to have a strong country effect on the research field (Persson 2010). The USA, the largest producer of scientific publications, to an extent owes this domination to the size effect (Schubert and Braun 1990).

Generally, the ranking of first author $\left(R_{P_{F A}}\right)$ was parallel to that of corresponding author $\left(R_{P_{F A}}\right)$ but different in the sequence of total number of papers in most internationally collaborative countries (Table 5). Particularly, Russia ranked 8th in the number of ESI papers collaborating with China and 18th in first author ranking and corresponding author ranking, while Singapore ranked 16th in the number of ESI papers collaborating with China but 8th in first author ranking and 6th corresponding author ranking.

\section{Inter-institutional collaboration}

The characteristics and performance of academic institutions can be assessed by bibliometric indicators to some extent to assist decision-making by policy makers, researcher and students (Pouris 2007). Aiming to reveal Chinese institutions active in the scientific literature, the top 20 productive institutions with ESI paper are listed in Table 6. The most 
Table 5 The top 20 most frequently collaborative countries with China

\begin{tabular}{lcccc}
\hline Country/territory & $P_{E S I-C}$ & $R_{P_{E S I-C}}(\%)$ & $R_{P_{F A}}(\%)$ & $R_{P_{R P}}(\%)$ \\
\hline USA & 1215 & $1(28)$ & $1(14)$ & $1(14)$ \\
Germany & 339 & $2(7.9)$ & $4(1.6)$ & $4(1.5)$ \\
UK & 336 & $3(7.9)$ & $2(2.7)$ & $2(2.7)$ \\
Japan & 260 & $4(6.1)$ & $3(1.7)$ & $3(1.6)$ \\
France & 229 & $5(5.4)$ & $5(1.2)$ & $5(1.2)$ \\
Australia & 203 & $6(4.8)$ & $6(1.1)$ & $6(1.0)$ \\
Canada & 198 & $7(4.6)$ & $6(1.1)$ & $6(1.0)$ \\
Russia & 137 & $8(3.2)$ & $18(0.14)$ & $18(0.12)$ \\
Italy & 135 & $9(3.2)$ & $9(0.73)$ & $9(0.68)$ \\
Netherlands & 127 & $10(3.0)$ & $13(0.42)$ & $13(0.42)$ \\
South Korea & 125 & $11(2.9)$ & $12(0.45)$ & $12(0.45)$ \\
Switzerland & $12(2.8)$ & $10(0.52)$ & $10(0.52)$ \\
Taiwan & 120 & $13(2.6)$ & $11(0.49)$ & $11(0.49)$ \\
India & 113 & $14(2.5)$ & $27(0.047)$ & $23(0.070)$ \\
Sweden & $14(2.5)$ & $16(0.19)$ & $16(0.19)$ \\
Singapore & 108 & $16(2.5)$ & $8(1.0)$ & $6(1.0)$ \\
Brazil & 108 & $17(2.2)$ & $27(0.047)$ & $27(0.047)$ \\
Spain & 107 & $18(1.9)$ & $15(0.23)$ & $14(0.23)$ \\
Poland & 94 & $19(1.8)$ & $24(0.070)$ & $27(0.047)$ \\
Belgium & $83(1.4)$ & $14(0.26)$ & $14(0.23)$ \\
\hline & 78 & & &
\end{tabular}

productive institution was the Chinese Academy of Sciences (CAS) accounting for 24\%, the China's highest academic institution in natural sciences, a major advisory body to the government on science and technology related issues, and a national comprehensive research and development center in natural sciences and high technology areas. CAS has dominated publications with a contribution more than $25 \%$ of total publications from 1981 to 1985 (Arunachalam et al. 1993). However, a bias appeared because the Chinese Academy of Sciences has over 100 branches in different cities (Li et al. 2009a). CAS consists of the Academic Divisions and various subordinate institutions. There are six Academic Divisions: Mathematics and Physics, Chemistry, Life Sciences and Medical Sciences, Earth Sciences, Technological Sciences, and Information Technological Sciences. The CAS has 12 branch offices located in Beijing, Shenyang, Changchun, Shanghai, Nanjing, Wuhan, Guangzhou, Chengdu, Kunming, Xi'an, Lanzhou, and Xinjiang. These are 113 institutions directly under CAS, including 92 research institutes (including three botanical gardens), six universities and supporting organizations (including two universities, one supporting organization, one documentation and information unit, two news and publication units), 12 management organizations that consist of the headquarters and branches, and three other units. These CAS branch offices and institutions are located in 22 provinces and municipalities throughout China. CAS staff even surpassed 50,000 since 2008 (http://cas.cn/). The publications of different institutions were pooled as one heading now, and publications divided into branches would result in different rankings. Other than the Chinese Academy of Sciences, the top three productive institutions were the University of Hong Kong, Peking University, and the University of Science and Technology of China. 


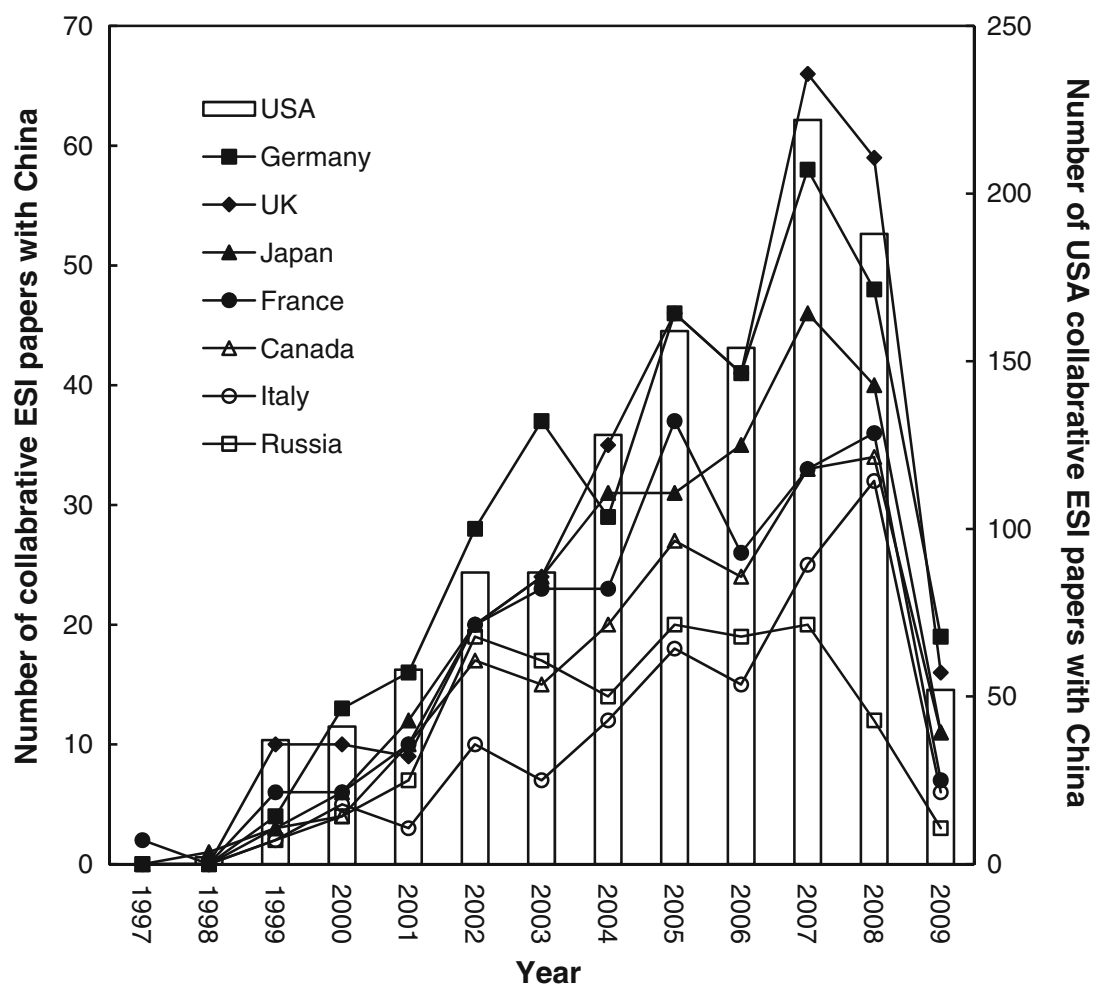

Fig. 5 The trends of international collaborations with eight industrial countries (G8) from 1997 to 2009

The development of productive institutions can partly be attributed to Chinese policy. Of the top 20 institutions, 13 productive universities were all included in the "985 Project" of China except for five universities located in Hong Kong, the Chinese Academy of Sciences and Donghua University, ranking 20th. The "985 Project" was launched by President Jiang Zemin, declaring "China must have a number of first-rate universities of international advanced level" on May 4, 1998. This project was divided into two phases. In the initial phase, nine universities were involved, all listed in the top 20 universities. Grants of more than US\$ 125 million each over a period of 3 years was given to these initial nine universities. In the second phase, the program was expanded until it has now reached almost 40 universities, most of which receive millions of dollar each year. Most of the funding goes to academic exchange, allowing Chinese academics to participate in conferences abroad, and attract world-renowned faculty and visiting scholars. Specially, Donghua University, which was not involved in the project characterized by textiles, the total number of the textile-related papers was in excess of the total number of textile papers from nine world-famous textile institutions in SCI (Science Citation Index), EI (The Engineering Index), and ISTP (Index to Scientific \& Technical Proceedings) for two consecutive years. With the exception of the Chinese Academy of Sciences, the University of Hong Kong ranked 1st in inter-institutionally collaborative papers, as the institution of affiliation of first author and corresponding author. Tsing Hua University ranked 5th in total papers, but 2 nd independent papers and in the 3 rd in the institutes of affiliation of first author and corresponding author (Table 6). 
Table 6 The top 20 most productive Chinese institutions

\begin{tabular}{lrccccc}
\hline Institution & $P_{E S I-C}$ & $R_{P_{E S I C}(\%)}$ & $R_{P_{S C P}}(\%)$ & $R_{P_{C C P}}(\%)$ & $R_{P_{F A}}(\%)$ & $R_{P_{R P}}(\%)$ \\
\hline Chinese Academy of Sciences & 1,006 & $1(24)$ & $1(22)$ & $1(25)$ & $1(14)$ & $1(14)$ \\
University of Hong Kong & 283 & $2(6.6)$ & $3(4.4)$ & $2(7.8)$ & $2(3.1)$ & $2(3.1)$ \\
Peking University & 245 & $3(5.7)$ & $6(3.7)$ & $3(6.8)$ & $4(2.8)$ & $4(2.8)$ \\
University of Science and & 193 & $4(4.5)$ & $5(3.9)$ & $5(4.8)$ & $5(2.1)$ & $5(2.1)$ \\
$\quad$ Technology of China & & & & & & \\
Tsing Hua University & 189 & $5(4.4)$ & $2(4.6)$ & $6(4.4)$ & $3(3.0)$ & $3(2.9)$ \\
Chinese University of Hong Kong & 176 & $6(4.1)$ & $13(1.7)$ & $4(5.4)$ & $7(2.0)$ & $7(1.9)$ \\
Hong Kong University of Science & 154 & $7(3.6)$ & $4(4.1)$ & $10(3.4)$ & $6(2.0)$ & $6(2.1)$ \\
$\quad$ \& Technology & & & & & & \\
City University of Hong Kong & 142 & $8(3.3)$ & $12(2.0)$ & $7(4.0)$ & $11(1.5)$ & $11(1.5)$ \\
Shanghai Jiao Tong University & 135 & $9(3.2)$ & $7(2.4)$ & $8(3.6)$ & $8(1.7)$ & $8(1.7)$ \\
Zhejiang University & 130 & $10(3.0)$ & $7(2.4)$ & $9(3.4)$ & $9(1.6)$ & $9(1.6)$ \\
Fudan University & 121 & $11(2.8)$ & $7(2.4)$ & $11(3.1)$ & $10(1.5)$ & $10(1.5)$ \\
Nanjing University & 102 & $12(2.4)$ & $10(2.2)$ & $12(2.5)$ & $12(1.4)$ & $12(1.4)$ \\
Nankai University & 83 & $13(1.9)$ & $10(2.2)$ & $13(1.8)$ & $14(1.1)$ & $14(1.1)$ \\
Jilin University & 71 & $14(1.7)$ & $13(1.7)$ & $15(1.6)$ & $15(0.91)$ & $15(0.92)$ \\
Harbin Institute of Technology & 62 & $15(1.5)$ & $17(1.5)$ & $16(1.4)$ & $13(1.2)$ & $13(1.2)$ \\
Hong Kong Polytech University & 61 & $16(1.4)$ & $24(0.88)$ & $14(1.7)$ & $17(0.87)$ & $15(0.92)$ \\
Sun Yat Sen University & 57 & $17(1.3)$ & $17(1.5)$ & $22(1.3)$ & $18(0.84)$ & $17(0.85)$ \\
Shandong University & 54 & $18(1.3)$ & $22(1.0)$ & $16(1.4)$ & $26(0.56)$ & $26(0.56)$ \\
Sichuan University & 51 & $19(1.2)$ & $15(1.6)$ & $26(1.0)$ & $20(0.70)$ & $20(0.68)$ \\
Donghua University & 47 & $20(1.1)$ & $15(1.6)$ & $35(0.86)$ & $16(0.89)$ & $17(0.85)$ \\
\hline & & & & & &
\end{tabular}

\section{Most-cited ESI papers}

A most-cited paper reflected its high recognition and representation in the scientific community (Aksnes 2003). Identifying most-cited papers is one method of assessing the drivers of progress and serves as a statement of strength and impact (Paladugu et al. 2002; Baltussen and Kindler 2004; Ponce and Lozano 2010). The most frequently cited ESI paper in each of 22 ESI fields were identified and listed by published year, first authors, corresponding authors, number of authors, countries, document types, paper titles, and $C_{2009}$ (Table 7). The six top papers, 3 articles and 3 reviews, cited more than 1,000 times were found in the fields of molecular biology \& genetics, physics, clinical medicine, chemistry, plant $\&$ animal science, and geosciences. However, the top papers in multidisciplinary and general social sciences were found to have 143 and 133 citations respectively. The mostcited top paper was a review titled "initial sequencing and analysis of the human genome", which received 7,425 citations in molecular biology \& genetics by 243 authors from 8 countries: USA, UK, Japan, France, Germany, China, Ireland, and Israel. Of these top six papers, five were written by at least 46 authors and only one, titled in chemistry "a chemically functionalizable nanoporous material $\left[\mathrm{Cu}_{3}(\mathrm{TMA})_{2}\left(\mathrm{H}_{2} \mathrm{O}\right)_{3}\right]_{n}$ ", which was cited 1,222 times from its publication to 2009 , was by five authors from China and the UK. The top papers in engineering, molecular biology \& genetics, physics, and plant $\&$ animal science had more than 100 authors from 9, 8, 20, and 2 countries respectively. The only single author top paper titled "in search of golden rules: comment on hypothesis-testing 


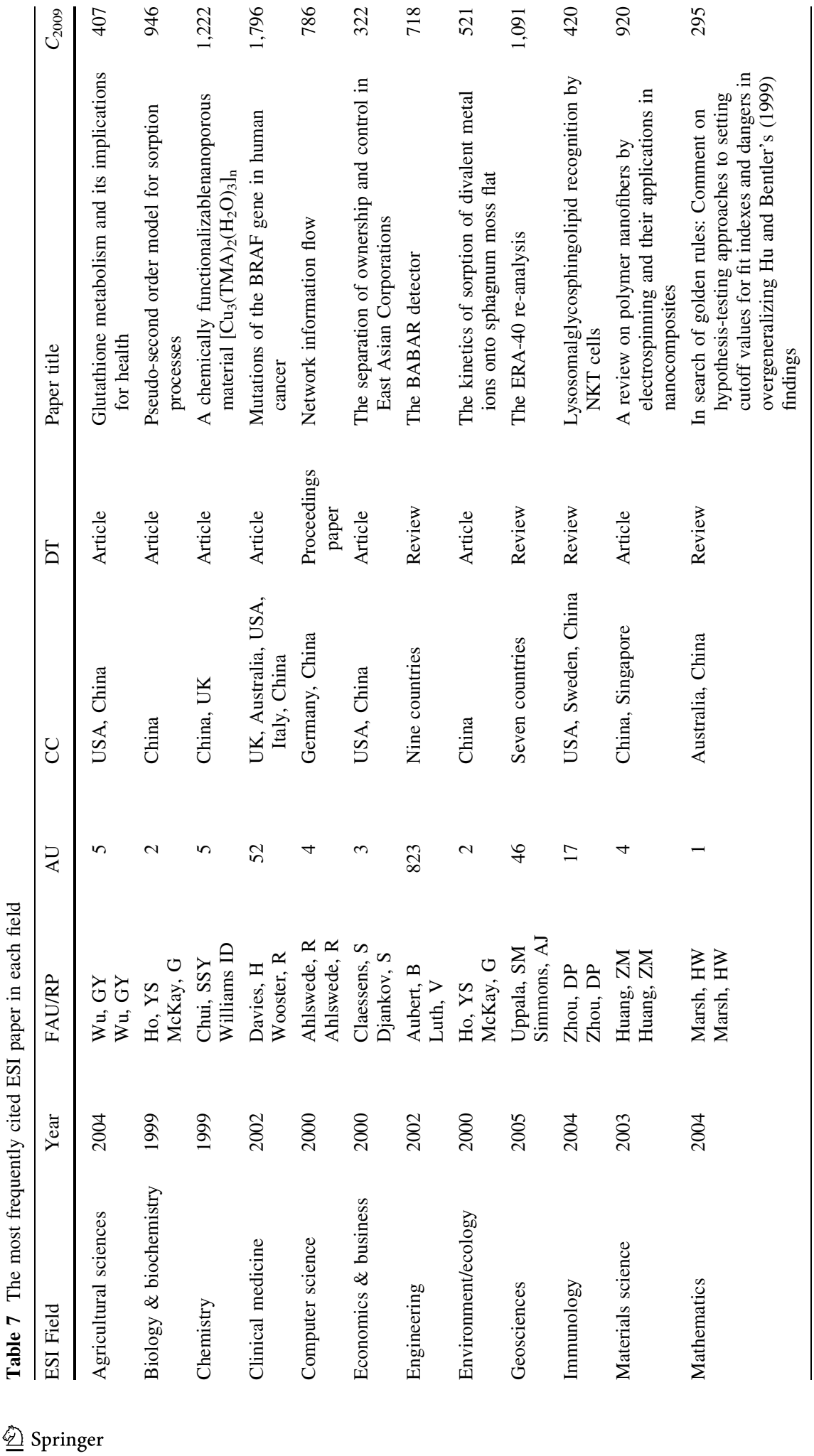




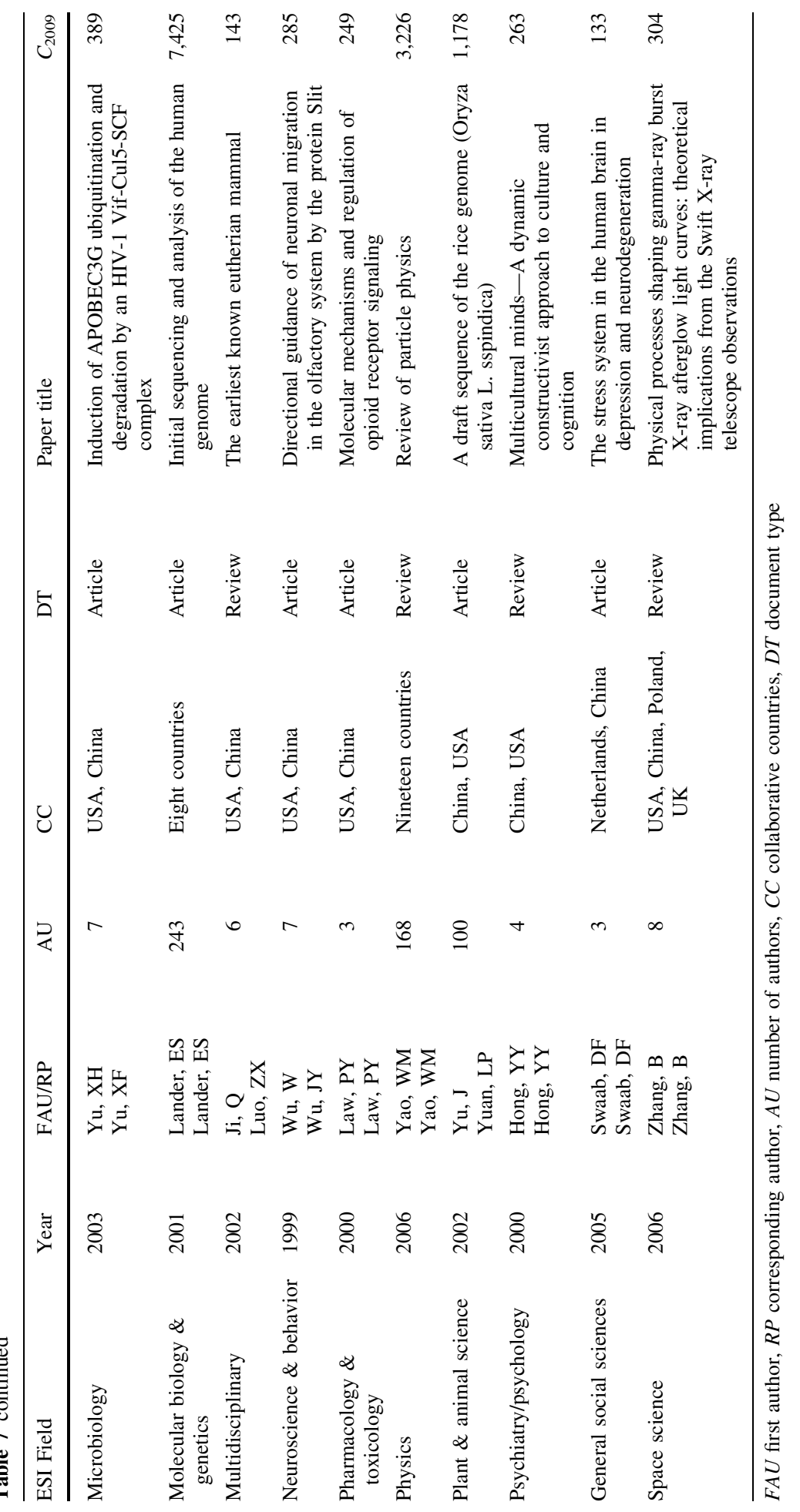


approaches to setting cutoff values for fit indexes and dangers in overgeneralizing $\mathrm{Hu}$ and Bentler's (1999) findings" was published by H. W. Marsh from both Australia and China in the mathematics field. Of the top papers in 22 ESI fields, three were issued in 1999, five in 2000, one in 2001, four in 2002, two in 2003, three in 2004, and two each in 2005 and 2006. The article "review of particle physics" published in 2006 with 168 authors from 20 countries in the physics field had 3,226 citations. Ten papers were published by the same authors (first author and corresponding author). Two papers by the same first author and corresponding author included Z.M. Huang from Tongji University in materials science and Y.Y. Hong from Hong Kong University of Science \& Technology in psychiatry/ psychology. Moreover, Y.S. Ho and G. McKay from Hong Kong University of Science \& Technology were only first and corresponding authors who published two top articles in both biology \& biochemistry and environment/ecology. These top papers were the only two papers independent of China. It has been noted that China internationally collaborative publications have increased and their citation impact differs among subject categories (Zhou and Glanzel 2010). International papers in most fields had higher impact than that of publications independent of China.

\section{Conclusions}

The features of China's highly cited papers in the ESI database were presented based on the production and citations by overall performance, journals and subject categories, international and inter-institutional collaboration, and most cited papers. Above all, China has developed rapidly in scientific performance in 22 fields during the period 1999-2009. Chemistry and physics were the two most productive fields to China's SCI papers while materials science, engineering and mathematics conducted better with the highest proportion to China's ESI papers. Secondly, China ESI papers were published in 870 journals in 137 SCI categories in JCR in 2008. Advanced Materials, Journal of the American Chemical Society, Physical Review Letters, and Angewandte Chemie-International Edition were the four journals included more than 100 ESI papers. Meanwhile, 51\% of ESI papers were published in the SCI categories of multidisciplinary chemistry, multidisciplinary materials science, physical chemistry, and applied physics. In terms of international collaboration, $47 \%$ of all China ESI papers were international collaborations with 101 countries in which G8 took overwhelming majority of the international collaboration. Moreover, the USA dominated in both first author and responding authors in internationally collaborative ESI papers with China. For national inter-institutional collaboration, the Chinese Academy of Sciences was the most productive institution, and the other most productive universities were involved in the "985 Project" or located in Hong Kong. Furthermore, international collaboration enhanced the citation rate of papers in most fields. Finally, an overwhelming number of the most cited papers were published by many authors with prominent international collaboration with China, while China's most-cited ESI independent papers were only in category of biology \& biochemistry and environment/ecology.

\section{References}

Aksnes, D. W. (2003). Characteristics of highly cited papers. Research Evaluation, 12, 159-170.

Almeida, J. A. S., Pais, A. A. C. C., \& Formosinho, S. J. (2009). Science indicators and science patterns in Europe. Journal of Informetrics, 3, 134-142. 
Arunachalam, S., Singh, U. N., \& Sinha, R. (1993). The sleeping dragon wakes up: A scientometric analysis of the growth of science and the usage of journals in China. Current science, 65, 809-822.

Baltussen, A., \& Kindler, C. H. (2004). Citation classics in critical care medicine. Intensive Care Medicine, 30, 902-910.

Chen, T. J., Chen, Y. C., Hwang, S. J., \& Chou, L. F. (2007). The rise of China in gastroenterology? A bibliometric analysis of ISI and Medline databases. Scientometrics, 69, 539-549.

Chiu, W. T., \& Ho, Y. S. (2005). Bibliometric analysis of homeopathy research during the period of 1991 to 2003. Scientometrics, 63, 3-23.

Cronin, B., Snyder, H., \& Atkins, H. (1997). Comparative citation rankings of authors in monographic and journal literature: A study of sociology. Journal of Documentation, 53, 263-273.

de Haan, J. (1997). Authorship patterns in Dutch sociology. Scientometrics, 39, 197-208.

Fu, H. Z., Ho, Y. S., Sui, Y. M., \& Li, Z. S. (2010). A bibliometric analysis of solid waste research during the period 1993-2008. Waste Management, 30, 2410-2417.

Garfield, E., \& Pudovkina, A. I. (2003). From materials science to nano-ceramics: Citation analysis identifies the key journals and players. Journal of Ceramic Processing Research, 4, 155-167.

Garfield, E., \& Welljams-Dorof, A. (1992). Citation data: Their use as quantitative indicators for science and technology evaluation and policy-making. Current Contents, 49, 5-13.

Glänzel, W. (1996). A bibliometric approach to social sciences. National research performances in 6 selected social science areas, 1990-1992. Scientometrics, 35, 291-307.

Glänzel, W. (2000). Science in Scandinavia: A bibliometric approach. Scientometrics, 48, 121-150.

Glänzel, W., Schubert, A., \& Braun, T. (2002). A relational charting approach to the world of basic research in twelve science fields at the end of the second millennium. Scientometrics, 55, 335-348.

Guan, J., \& Gao, X. (2008). Comparison and evaluation of Chinese research performance in the field of bioinformatics. Scientometrics, 75, 357-379.

Guan, J. C., \& Ma, N. (2007a). China's emerging presence in nanoscience and nanotechnology-A comparative bibliometric study of several nanoscience 'giants'. Research Policy, 36, 880-886.

Guan, J. C., \& Ma, N. (2007b). A bibliometric study of China's semiconductor literature compared with other major Asian countries. Scientometrics, 70, 107-124.

Halpenny, D., Burke, J., McNeill, G., Snow, A., \& Torreggiani, W. C. (2010). Geographic origin of publications in radiological journals as a function of GDP and percentage of GDP spent on research. Academic Radiology, 17, 768-771.

Hannerz, M. (2010). Top-cited articles 2001-2009. Scandinavian Journal of Forest Research, 25, 1-2.

He, T. W. (2009). International scientific collaboration of China with the G7 countries. Scientometrics, 80, 571-582.

Ho, Y. S., Satoh, H., \& Lin, S. Y. (2010). Japanese lung cancer research trends and performances in Science Citation Index. Internal Medicine, 49, 2219-2228.

Hoeffel, C. (1998). Journal impact factors. Allergy, 53(12), 1225.

Hsieh, W. H., Chiu, W. T., Lee, Y. S., \& Ho, Y. S. (2004). Bibliometric analysis of patent ductus arteriosus treatments. Scientometrics, 60, 205-215.

Hu, J., Ma, Y. W., Zhang, L., Gan, F. X., \& Ho, Y. S. (2010). A historical review and bibliometric analysis of research on lead in drinking water field from 1991 to 2007. Science of the Total Environment, 408, $1738-1744$.

Huang, K. G. (2010). China's innovation landscape. Science, 329, 632-633.

Jeenah, M., \& Pouris, A. (2008). South African research in the context of Africa and globally. South African Journal of Science, 104, 351-354.

Jin, B., \& Rousseau. R. (2005). China's quantitative expansion phase: Exponential growth but low impact. In: Ingwersen, P., \& Larsen, B. (Eds.) ISSI 2005: Proceedings of the 10th international conference of the international society for scientometrics and informetrics (pp. 362-370). Stockholm, Sweden: Karolinska University Press, 1-2.

Katz, J. S., \& Hicks, D. (1997). How much is a collaboration worth? A calibrated bibliometric model. Scientometrics, 40, 541-554.

Li, Z., \& Ho, Y. S. (2008). Use of citation per publication as an indicator to evaluate contingent valuation research. Scientometrics, 75, 97-110.

Li, J. F., Zhang, Y. H., Wang, X. S., \& Ho, Y. S. (2009a). Bibliometric analysis of atmospheric simulation trends in meteorology and atmospheric science journals. Croatica Chemica Acta, 82, 695-705.

Li, L. L., Ding, G. H., Feng, N., Wang, M. H., \& Ho, Y. S. (2009b). Global stem cell research trend: Bibliometric analysis as a tool for mapping of trends from 1991 to 2006. Scientometrics, 80, 41-60.

Malarvizhi, R., Wang, M. H., \& Ho, Y. S. (2010). Research trends in adsorption technologies for dye containing wastewaters. World Applied Sciences Journal, 8, 930-942. 
Mao, N., Wang, M. H., \& Ho, Y. S. (2010). A bibliometric study of the trend in articles related to risk assessment published in Science Citation Index. Human and Ecological Risk Assessment, 16, 801-824.

Martin, B. R., \& Irvine, J. (1983). Assessing basic research: Some partial indicators of scientific progress in radio astronomy. Research Policy, 12, 61-90.

Mervis, J. (2010). Science Indicators. Trends document China's prowess. Science, 327, 407-408.

Moed, H. F. (2005). Citation analysis in research evaluation. The Netherlands: Springer.

Moed, H. F., Burger, W. J. M., Frankfort, J. G., \& van Raan, A. F. J. (1985). The use of bibliometric data for the measurement of university research performance. Research Policy, 14, 131-149.

Moed, H. F., de Bruin, R. E., \& Van Leeuwen, T. H. N. (1995). New bibliometric tools for the assessment of national research performance: Database description, overview of indicators and first applications. Scientometrics, 33, 381-422.

Paladugu, R., Schein, M., Gardezi, S., \& Wise, L. (2002). One hundred citation classics in general surgical journals. World Journal of Surgery, 26, 1099-1105.

Persson, O. (2010). Are highly cited papers more international? Scientometrics, 83, 397-401.

Ponce, F. A., \& Lozano, A. M. (2010). Highly cited works in neurosurgery. Part I: The 100 top-cited papers in neurosurgical journals. A review. Journal of Neurosurgery, 112, 223-232.

Pouris, A. (1989). Strengths and weaknesses of South African science. South African Journal of Science, $85,623-626$.

Pouris, A. (2007). The international performance of the South African academic institutions: A citation assessment. Higher Education, 54, 501-509.

Rehn, C., Kronman, U., \& Wadskog, D. (2007). Bibliometric indicators-definitions and usage at Karolinska Institutet. Karolinska Institutet.

Rinia, E. J., van Leeuwen, T. H. N., van Vuren, H. G., \& van Raan, A. F. J. (1998). Comparative analysis of a set of bibliometric indicators and central peer review criteria: Evaluation of condensed matter physics in the Netherlands. Research Policy, 27, 95-107.

Schubert, A., \& Braun, T. (1990). International collaboration in the sciences, 1981-1985. Scientometrics, 19, 3-10.

Schubert, A., Glänzel, W., \& Braun, T. (1989). Scientometric datafiles: A comprehensive set of indicators on 2649 journals and 96 countries in all major science fields and subfields 1981-1985. Scientometrics, 16, 3-478.

Schwartz, F., \& Fang, Y. C. (2007). Citation data analysis on hydrogeology. Journal of the American Society for Information Science and Technology, 58, 518-525.

Seng, L. B., \& Willett, P. (1995). The citedness of publications by United-Kingdom library-schools. Journal of Information Science, 21, 68-71.

Shadgan, B., Roig, M., HajGhanbari, B., \& Reid, W. D. (2010). Top-cited articles in rehabilitation. Archives of Physical Medicine and Rehabilitation, 91, 806-815.

Soteriades, E. S., \& Falagas, M. E. (2005). Comparison of amount of biomedical research originating from the European Union and the United States. British Medical Journal, 331, 192-194.

Vinkler, P. (1988). An attempt of surveying and classifying bibliometric indicators for scientometric purposes. Scientometrics, 13, 239-259.

Wang, M. H., Yu, T. C., \& Ho, Y. S. (2010). A bibliometric analysis of the performance of Water Research. Scientometrics, 84, 813-820.

Yamazaki, S. (1994). Research activities in life sciences in Japan. Scientometrics, 29, 181-190.

Zhang, L., Wang, M. H., Hu, J., \& Ho, Y. S. (2010). A review of published wetland research, 1991-2008: Ecological engineering and ecosystem restoration. Ecological Engineering, 36, 973-980.

Zhou, P., \& Glanzel, W. (2010). In-depth analysis on China's international cooperation in science. Scientometrics, 82, 597-612.

Zhou, P., \& Leydesdorff, L. (2006). The emergence of China as a leading nation in science. Research Policy, 35, 83-104.

Zhou, P., \& Leydesdorff, L. (2008). China ranks second in scientific publications since 2006. ISSI Newletter, 4, 7-9.

Zhou, P., \& Leydesdorff, L. (2009). Chemistry in China-A bibliometric view. Chimica Oggi-Chemistry Today, 27, 19-22.

Zhou, F., Guo, H. C., Ho, Y. S., \& Wu, C. Z. (2007). Scientometric analysis of geostatistics using multivariate methods. Scientometrics, 73, 265-279. 